\title{
Effects of Biodiesel Fuel Use on Vehicle Emissions
}

\author{
Larry G. Anderson ${ }^{1, *}$ \\ ${ }^{1}$ University of Colorado Denver, Denver, Colorado, USA \\ * Corresponding author. Tel: +1 3035562963, Fax: +1 3035564776, E-mail: larry.anderson@ucdenver.edu
}

\begin{abstract}
Many countries are using and considering the increased use of biodiesel blended fuels to slow their growth of fossil fuel use for transportation purposes. Before the use of biodiesel fuels increase, it is critical that we understand the effect of using biodiesel blends on vehicle emissions, so that we better understand what air quality impacts to expect. Many previous reviews of biodiesel effects on emissions have combined all of the emissions data available to construct a single value for the effects on pollutant emissions. This includes combining emissions data from both light-duty and heavy-duty diesel vehicles and engines, combining vehicle data from chassis dynamometer and on-road emissions testing. In this review, we will analyze the effects on vehicle emissions of switching from petroleum diesel fuel to biodiesel blended fuels for light-duty and heavyduty vehicles, separately. We will not include engine emissions data in this analysis. For the heavy-duty vehicles, we will also separate results for on-road emissions testing from chassis dynamometer testing. The emissions of regulated pollutants will be evaluated, including hydrocarbons (HC), nitrogen oxides (NOx), carbon monoxide (CO) and particulate matter (PM), as well as carbon dioxide $\left(\mathrm{CO}_{2}\right)$ emissions and fuel economy. In these analyses, we have found some statistically significant differences in the effects of biodiesel use on the emissions between heavy-duty vehicles based on dynamometer and on-road emissions testing, and light-duty vehicle dynamometer data. For vehicle emissions from heavy-duty vehicle tested using a dynamometer and onroad emissions techniques, the emissions of $\mathrm{CO}, \mathrm{CO}_{2}$ and $\mathrm{PM}$ were found not to be significantly different for B20, but the HC, NOx and fuel economy results were significantly different. The results of the heavy-duty and light-duty dynamometer emissions were found to not differ significantly for any pollutant, other than PM emissions when B20 blended fuels were used. When the results of the emissions studies were not significantly different, the results were combined to determine the effect of biodiesel use on vehicle emissions.
\end{abstract}

Keywords: Renewable fuels, Biodiesel, Vehicle emissions, Regulated air pollutants, Hazardous air pollutants

\section{Introduction}

Many countries are evaluating a variety of alternative fuels for use in motor vehicles in an attempt to reduce greenhouse gas emissions and to improve the energy security of the country. Biodiesel and other biofuels are substitute fuels capable of replacing fossil fuels on a large scale in the transportation sector. Although biodiesel currently accounts for a small portion of the total diesel fuel used, increasing its use requires that we understand the impact that biodiesel could have on vehicle emissions, and ultimately on air quality.

Vehicle emissions are affected by the fuel that is used. There have been several reviews of the effects of biodiesel fuel use on emissions, but many of these have used engine emissions tests in addition to or instead of vehicle emissions tests [1-4]. Emission measurement methods include engine and chassis dynamometer tests, tunnel studies, and more recently, remote sensing and portable (or on-board) emissions monitoring systems. Engine dynamometer systems are quite useful for research purposes, but because these systems test only the engine, they are missing many factors that may affect the real-world emissions of vehicles. Chassis dynamometer studies test the entire vehicle and can use realistic driving cycles which are expected to produce more representative emissions results. Chassis dynamometer testing is more complicated and expensive than engine testing, so less of that data is available. Remote sensing and on-board emissions measurements have also been used to assess the effects of using different fuels on vehicle emissions. Remote sensing uses spectroscopic measurements of a vehicle that passes through the light beam to measure the concentrations of emitted pollutants. These measurements provide only a snapshot of the emissions at a particular 
location and thus cannot characterize an entire operating cycle for a vehicle. On-board emissions measurement systems offer the advantage of being able to capture real-world emissions during an entire operating cycle for the vehicle. In this review, we will focus on the analysis of vehicle emissions data that is more representative of real-world operating conditions, from chassis dynamometer and on-board emissions measurement systems.

\section{Analysis Approach}

In this paper, we will assess the impact of biodiesel fuel use by looking at the relative value of a property, such as pollutant emissions from a biodiesel blended fuel divided by that from conventional diesel fuel use for a particular vehicle. This reduces some of the variability in analyzing vehicle emissions data, since vehicles that emit larger or smaller quantities of a pollutant when using diesel fuel are expected to also emit larger or smaller quantities of that pollutant when using a biodiesel blended fuel. If the use of biodiesel fuels does not affect the property being studied the relative value will be 1 . For example, a value of 1.12 indicates that the property has increased by $12 \%$ with biodiesel fuel use and a value of 0.89 would indicate a decrease by $11 \%$ with biodiesel fuel use. In this analysis, at least twenty measurements were required to assess statistical significance. This minimum number of measurements was used in an attempt to assure the representativeness of the data. These relative emissions and fuel economy data were tested for normality using the Lilliefors test. These data were found not to be significantly different from a normal distribution. This allows the use of conventional statistical techniques in these analyses.

\section{Heavy-Duty Diesel Vehicle Emissions}

Quite a bit of data exists for biodiesel blended fuels in heavy-duty (HD) diesel vehicles where the emissions were measured using chassis dynamometers and on-road using portable emissions monitoring systems (PEMS). These two different sources of emissions data will be analyzed separately.

\subsection{Heavy-Duty Diesel Chassis Dynamometer Studies}

The data used to assess the effect of biodiesel fuels use on HD vehicles from dynamometer studies comes from 19 different studies and includes 124 different tests. Much of the data on the emissions effects of biodiesel blended fuels from chassis dynamometer studies of HD diesel vehicles was for $20 \%$ blends of biodiesel with petroleum diesel (B20) and neat biodiesel (B100) fuels. Since a total of twenty valid measurements are required in order to assess the significance of the effect of biodiesel blended fuels on a measurement, only hydrocarbons (HC), nitrogen oxides (NOx) and carbon monoxide (CO) had sufficient data for the assessment of both B20 and B100 biodiesel, while sufficient data was also available for B20 blends to assess the significance of the effects on carbon dioxide $\left(\mathrm{CO}_{2}\right)$, particulate matter (PM) and fuel economy. For these HD vehicles, the use of biodiesel led to a decrease for hydrocarbon emissions of $5.7 \pm 4.4 \%$ (95\% confidence interval) for B20 and $23.0 \pm 9.2 \%$ for B100, a decrease for CO emissions of $4.1 \pm 6.4 \%$ (not significant) for B20 and $24.0 \pm$ $7.2 \%$ for B100, and an increase in NOx emissions of $3.5 \pm 2.3 \%$ for B20 and $9.0 \pm 2.8 \%$ for $\mathrm{B} 100$. The use of $\mathrm{B} 20$ blended fuels also led to a decrease for $\mathrm{CO}_{2}$ emissions of $0.4 \pm 1.0 \%$ (not significant), for PM emissions of $13.3 \pm 5.1 \%$, and for fuel economy of $2.6 \pm 1.2 \%$. There was an insufficient quantity of emissions test data for other biodiesel blends to characterize the variability in the emissions data, and to allow one to reliably assess the significance of the effects on the emissions of HD vehicles tested using chassis dynamometers. 


\subsection{Heavy-Duty Diesel On-Road Vehicle Emissions Studies}

The data used to assess the effect of biodiesel fuels use on HD vehicles from on-road studies comes from 14 different studies and includes 94 different tests. Almost all of the data for these on-road vehicle emissions tests of HD diesel vehicles are for B20 blends. For these HD vehicles, the use of B20 blends led to a decrease for hydrocarbon emissions of $21.7 \pm 4.4 \%$ (95\% confidence interval), a decrease for CO emissions of $6.6 \pm 5.4 \%$, and a decrease in NOx emissions of $3.3 \pm 3.4 \%$ (not significant). The use of B20 blended fuels also led to an increase for $\mathrm{CO}_{2}$ emissions of $3.0 \pm 3.6 \%$ (not significant), a decrease for PM emissions of $15.2 \pm$ $6.0 \%$, and an increase for fuel economy of $6.3 \pm 8.1 \%$ (not significant). One of the major complications of the on-road PEMS testing for evaluating different fuels is the much poorer matching of the operating conditions of the vehicles with these different fuels. This generally leads to increased variability in the results.

\subsection{Differences between Chassis Dynamometer and On-Road Heavy-Duty Vehicle Emissions Data}

The chassis dynamometer and on-road vehicle emissions data for HD vehicles were tested to determine if the results were significantly different for these two testing procedures. It was found that there was no significant difference in the results of the emissions test methods for the $\mathrm{CO}, \mathrm{CO}_{2}$ and PM data using B20 blends. However, the results were significantly different for the HC, NOx and fuel economy data between the two data sets. For the HC data, B20 blends led to a significant decrease in HC emissions in both cases, but only about $5.7 \%$ for the dynamometer studies and $21.7 \%$ for the on-road studies. The decrease from the on-road studies with B20 were similar to the effects of B100 seen with the dynamometer data. For the NOx data, B20 blends led to a significant increase in NOx emissions of about $3.5 \%$ for the dynamometer studies, while there was a 3.3\% decrease (not significant) in NOx emissions in the on-road studies. The data continues to support an increase in NOx emissions with biodiesel blends in HD diesel vehicles. In the case of the fuel economy data, B20 blends led to significantly lower fuel economy of about $2.6 \%$ from the dynamometer studies, but led to a $5.7 \%$ increase (not significant) in fuel economy for the on-road studies. The data continues to support a decrease in fuel economy with B20 biodiesel blends in HD vehicles.

Since there was no significant difference in the results of the dynamometer and on-road emissions studies using $\mathrm{B} 20$ blends for the $\mathrm{HD}$ vehicle emissions of $\mathrm{CO}, \mathrm{CO}_{2}$ and $\mathrm{PM}$, these data sets were combined and the significance of the effects on this larger pooled data set were assessed. For the CO emissions data with B20, a 4.1\% decrease (not significant) was found from the dynamometer studies and a significant $6.6 \%$ decrease was found from the on-road studies. With the combined data set, a significant decrease of $5.3 \pm 4.1 \%$ was found for $\mathrm{CO}$ using B20 blends. For the $\mathrm{CO}_{2}$ emissions data with B20, a $0.4 \%$ decrease (not significant) was found from the dynamometer studies and a 3.0\% increase (not significant) was found from the on-road studies. With the combined data set, a $1.6 \pm 2.2 \%$ increase (not significant) was found for $\mathrm{CO}_{2}$ using $\mathrm{B} 20$ blends. These data support the conclusion that the use of B20 biodiesel fuels has no significant effects on the emissions of $\mathrm{CO}_{2}$. For the PM emissions data with B20, a significant 13.8\% decrease was found from the dynamometer studies and a significant $15.2 \%$ decrease was found from the on-road studies. With the combined data set, a significant decrease of $14.5 \pm 3.9 \%$ was found for PM using B20 blends.

\section{Light-Duty Diesel Vehicle Emissions using Chassis Dynamometers}

The data used to assess the effect of biodiesel fuels use on light-duty (LD) vehicles from dynamometer studies comes from 47 different studies and includes 259 different tests. LD 
diesel vehicle emissions have been measured almost exclusively by use of chassis dynamometers. PEMS have not been used extensively in the study of LD diesel vehicle emissions. The available data consists of a number of studies conducted in North America, Europe, Asia and Australia. The studies conducted in North America tend to be dominated by studies of larger vehicles, including pickup trucks, while those elsewhere in the world include a larger fraction of cars, passenger and delivery vans. This data set also includes biodiesel fuels that are made from different biooil feedstock (soy, rapeseed, canola, palm, coconut, used cooking oils, animal fats, etc.). The emissions test data for light-duty vehicles contains many more tests with varying biodiesel percentages, not largely B20 and B100.

Fig. 1 shows the relative emissions of $\mathrm{HC}, \mathrm{NO}_{\mathrm{x}}, \mathrm{CO}, \mathrm{CO}_{2}, \mathrm{PM}$ and fuel economy effects of using various biodiesel blended fuels based on chassis dynamometer testing of LD vehicles from a number of different studies. From this figure it is clear that there is a relatively large quantity of data available with different biodiesel percentages, and that there is considerable variability in the individual measurements of the relative emissions effects of biodiesel blended fuels. Similar figures are seen when one looks at the HD diesel emissions data. For the regulated pollutant emissions, there are more that 20 sets of test results available for the B5, B10, B20, B30, B50 and B100 biodiesel blends. This allows the evaluation of statistical significance of the effects of these blends on vehicle emissions.

For the LD diesel vehicle emissions we observed the following effects of the biodiesel blended fuels. For the HC emissions the effects of the biodiesel blends is an increase of $1.6 \pm$ $4.5 \%$ (95\% confidence interval) for B5, an increase of $4.2 \pm 5.2 \%$ for B10, a decrease of $4.1 \pm$ $5.5 \%$ for B20, a decrease of $0.3 \pm 5.4 \%$ for B30, a decrease of $0.9 \pm 10.3 \%$ for B50, and a decrease of $5.8 \pm 14.8 \%$ for B100. None of the observed effects on hydrocarbon emissions are statistically significant. For NOx emissions the effects of the biodiesel blends was an increase of $1.1 \pm 2.7 \%$ for B5, of $5.1 \pm 2.3 \%$ for B10, of $5.8 \pm 2.2 \%$ for B20, of $7.2 \pm 2.7 \%$ for B30, of $7.3 \pm 3.5 \%$ for B50, and of $6.5 \pm 3.5 \%$ for B100. The biodiesel blend effect on NOx emissions is consistently a statistically significant increase for all of these blend levels, except B5. The effect of the biodiesel blends on CO emissions show a decrease of $0.7 \pm 2.9 \%$ for B5, an increase of $2.7 \pm 5.9 \%$ for B10, a decrease of $5.5 \pm 3.5 \%$ for B20, an increase of $4.8 \pm 6.0 \%$ for B30, an increase of $4.7 \pm 10.8 \%$ for B50, and an increase of $12.9 \pm 14.3 \%$ for B100. For the $\mathrm{CO}$ emissions, none of the biodiesel blends above had a statistically significant effect, except the decrease observed for the $\mathrm{B} 20$ blend. For the $\mathrm{CO}_{2}$ emissions the effects of the biodiesel blends was a decrease of $2.0 \pm 2.3 \%$ for B5, a decrease of $1.1 \pm 0.9 \%$ for B10, a decrease of $0.4 \pm 1.2 \%$ for B20, an increase of $1.1 \pm 1.4 \%$ for B30, an increase of $1.2 \pm 1.3 \%$ for $\mathrm{B} 50$, and an increase of $0.8 \pm 1.4 \%$ for $\mathrm{B} 100$. This data shows a small statistically significant decrease in $\mathrm{CO}_{2}$ emissions only for the $\mathrm{B} 10$ blend. None of the other results are statistically significant. The effect of the biodiesel blends on PM emissions show a decrease of $1.0 \pm 5.0 \%$ for B5, a decrease of $14.8 \pm 3.5 \%$ for B10, a decrease of $5.8 \pm 4.9 \%$ for B20, a decrease of $16.0 \pm 3.6 \%$ for $\mathrm{B} 30$, a decrease of $9.1 \pm 8.6 \%$ for $\mathrm{B} 50$, and a decrease of $7.0 \pm$ $14.8 \%$ for B100. The decrease observed for the B10, B20, B30 and B50 blends are statistically significant, and they are relatively large effects in the range of $6-16 \%$ decrease, but none of the other biodiesel blend levels resulted in a statistically significant effect. For the fuel economy results, only the B5, B10, B20, B30 and B50 blends had a sufficient quantity of data (more than 20 values) to assess the significance of the effects. The fuel economy was found to decrease (or fuel consumption increased) by $0.4 \pm 1.2 \%$ for B5, by $0.3 \pm 1.0 \%$ for B10, by $1.0 \pm 1.8 \%$ for B20, by $1.3 \pm 2.0 \%$ for B30, and by $1.9 \pm 2.5 \%$ for B50. None of the fuel economy effects are statistically significant. 

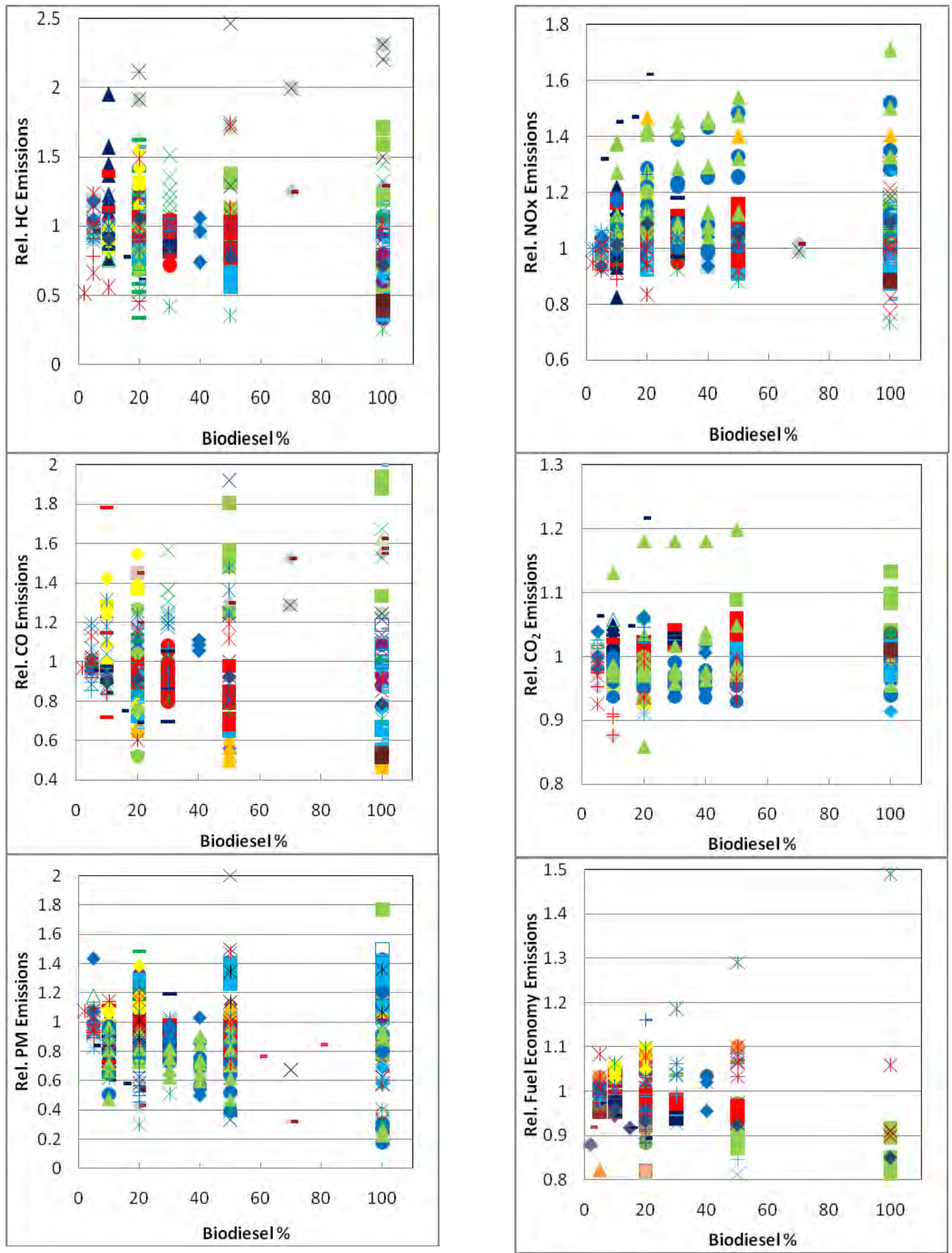

Fig. 1. Chassis dynamometer test results of relative emissions of hydrocarbons, nitrogen oxides, carbon monoxide, carbon dioxide, particulate matter, and vehicle fuel economy for biodiesel fuel relative to diesel fuel in light-duty diesel vehicles. 
Sufficient data exists to allow one to begin to explore the effects of biodiesel fuel use on the emissions of formaldehyde, acetaldehyde and total polycyclic aromatic hydrocarbons (PAH) for LD vehicles. The effects of the biodiesel blends on formaldehyde emissions were increases of $28.9 \pm 17.1 \%$ for B10, $27.5 \pm 21.8 \%$ for B20 and $34.9 \pm 8.7 \%$ for B30, while the effects on acetaldehyde emissions were increases of $40.7 \pm 76.1 \%$ for B10, $69.9 \pm 126 \%$ for B20 and $23.1 \pm 7.2 \%$ for B30. All of the increases found for formaldehyde emissions were statistically significant, but only the acetaldehyde emissions increase for B30 was statistically significant. The results for the effects of the biodiesel blends on the emissions of total PAH were confusing, with the total PAH emissions reduced by $8.3 \pm 6.4 \%$ for B10 and $8.9 \pm 9.8 \%$ for B20, while for the B30 and B100 blends, the total PAH emissions increased by $21.2 \pm 18.4 \%$ and $33.4 \pm 53.7 \%$ respectively. Only the results for B10 and B30 were statistically significant.

\section{Comparison of Heavy-Duty and Light-Duty Diesel Vehicle Emissions}

The only comparisons that can be made between HD and LD diesel vehicle emissions are for B20 blends, where sufficient data exists for the HD diesel dynamometer and on-road and LD dynamometer tests, and for $\mathrm{HC}$, NOx and $\mathrm{CO}$ emissions where sufficient data exists for HD and LD dynamometer tests with B100 fuels. For the HC emissions, we have found that the emissions from HD vehicles in the on-road emissions studies are significantly lower that the HD dynamometer test results. The HD on-road emissions results are also significantly lower than the LD dynamometer results, and the HD and LD dynamometer results are not significantly different from each other. The HD and LD dynamometer results have been combined for the B20 blend, resulting in an overall HC emissions decrease of $4.9 \pm 3.5 \%$ from the combined dynamometer data. Again for NOx emissions, the HD on-road emissions results were significantly lower than the HD dynamometer results and were significantly lower than the LD dynamometer results. There was no significant difference between the HD and LD dynamometer results for NOx. The HD and LD dynamometer results have been combined for the B20 blend, resulting in an overall NOx emissions increase of $4.7 \pm 1.6 \%$. For the CO emissions, the HD on-road emissions results were not significantly different that the HD dynamometer results, and the combined HD emissions results were not significantly different than the LD dynamometer results. The HD dynamometer and on-road emissions results, and the LD dynamometer emissions results were combined for the B20 blend, resulting in an overall $\mathrm{CO}$ emissions decrease of $5.4 \pm 2.9 \%$. For the $\mathrm{CO}_{2}$ emissions, the $\mathrm{HD}$ on-road emissions results were not significantly different that the HD dynamometer results, and the combined HD emissions results were not significantly different than the LD dynamometer results. The HD dynamometer and on-road emissions results and the LD dynamometer emissions results were combined for the B20 blend, resulting in an overall $\mathrm{CO}_{2}$ emissions increase of $0.9 \pm 1.5 \%$. For the PM emissions, the HD on-road emissions results were not significantly different that the HD dynamometer results, but the combined HD emissions results were significantly lower than the LD dynamometer results. The HD dynamometer and on-road emissions results were combined for the B20 blend, resulting in an overall PM emissions decrease of $14.5 \pm 3.9 \%$. The fuel economy from HD vehicles in the on-road studies are significantly higher than the HD dynamometer test results. The HD onroad fuel economy results are not significantly different from the LD dynamometer results, and the HD and LD dynamometer results are not significantly different from each other. The HD and LD dynamometer results have been combined for the B20 blend, resulting in an overall fuel economy decrease of $1.8 \pm 1.1 \%$.

For the HC emissions from B100 blends, we have found that the emissions from HD and LD dynamometer data are not significantly different. The HD and LD dynamometer results have been combined for the B100 blend, resulting in an overall HC emissions decrease of $13.4 \pm$ 
9.2\%. For the NOx emissions from B100 blends, the emissions from $\mathrm{HD}$ and LD dynamometer data are not significantly different. The HD and LD dynamometer results have been combined for the B100 blend, resulting in an overall NOx emissions increase of $7.5 \pm$ $2.4 \%$. For the $\mathrm{CO}$ emissions from the B100 blend, the heavy duty dynamometer results are significantly lower than the LD dynamometer results.

\section{Conclusions}

Most reviews of the effects of biodiesel blended fuels use on vehicle emissions combine all of the available data engine and vehicle, LD and HD to assess the effects. As has been found in this work this is not always a valid approach. In this work, we have only used vehicle emissions data, no engine data, and we have found some significant differences in subsets of this vehicle data.

In this work, it was found that there some of the emissions for HD diesel vehicles tested using dynamometers and on-road were significantly different. For B20 blends, the HC emissions for both test procedures led to significant decreases emissions in these emissions of $5.7 \%$ for the dynamometer studies and $21.7 \%$ for the on-road studies. In the cases of NOx emissions studies, a statistically significant increase in NOx emissions was found for B20 blends from the dynamometer data, while the on-road studies resulted in a 3.3\% decrease that was not significant. For fuel economy, the dynamometer data for B20 showed a significant decrease in fuel economy of $2.6 \%$, while the on-road data gave a $5.7 \%$ increase that was not significant. For each of these three measures for the two different sources of HD vehicle emissions data, the dynamometer data was significantly different from the on-road data. It is not be valid to combine data from the dynamometer and on-road studies of B20 blended fuels for HC and NOx emissions and fuel economy to determine the effects of using these fuels in HD vehicles. But since the B20 data for $\mathrm{CO}, \mathrm{CO}_{2}$ and PM emissions derived from these two different test procedures are not significantly different, it is valid to combine these data sets to assess the overall effects of B20 on these emissions from HD vehicles.

In comparing the results of studies on LD and HD vehicles for B20 blends, we have found no significant differences in HC and NOx emissions and fuel economy between the LD and HD dynamometer studies, and we have found no significant differences in emissions of CO and $\mathrm{CO}_{2}$ between the LD dynamometer and the combined HD dynamometer and on-road test data. But the PM emissions for B20 fuels are significantly different between the LD dynamometer and the combined HD dynamometer and on-road test data. Table 1 summarizes the statistically significant results for B20 blended fuels, where the HD and LD data are combined when there is no significant difference between the subsets of the data.

Being able to partition data to allow one to explore subsets of vehicle emissions data requires large quantities of data. Many other factors need to be explored, but there is a shortage of adequate data to be representative of these other factors. There is inadequate data available to allow one to assess the effects of biodiesel fuel use on emissions of hazardous air pollutants, such as benzene, 1,3-butadiene, etc. As seen in this work, there is sufficient data to begin exploring the effects on LD vehicle emissions of formaldehyde, acetaldehyde, and polycyclic aromatic hydrocarbons. We need much more data to begin assessing the effects of biodiesel fuel use on ultrafine particulate emissions, especially, particle number and particle size distributions in emissions. Different biodiesel feedstocks are more commonly used in different areas of the world, such as soy oil in North America, rapeseed oil in Europe and palm oil in southern parts of Asia. Additional vehicle emissions data is necessary to explore the effects of different biodiesel feedstocks on vehicle emissions. 
Table 1. Summary of statistically significant results for B20 and B100 biodiesel blends for combined $L D$ and HD dynamometer (dyno) and HD on-road emissions data.

\begin{tabular}{|c|c|c|c|c|c|}
\hline Emission & $\begin{array}{c}\text { Biodiesel } \\
\text { Blend }\end{array}$ & Tests & $\begin{array}{l}\text { Biodiesel } \\
\text { Effect }\end{array}$ & $\begin{array}{c}\text { 95\% Confidence } \\
\text { Interval }\end{array}$ & $\begin{array}{c}\text { Number of } \\
\text { Measurements }\end{array}$ \\
\hline $\mathrm{HC}$ & B20 & HD \& LD Dyno & $-4.9 \%$ & $\pm 3.5 \%$ & 204 \\
\hline $\mathrm{HC}$ & B20 & HD On-road & $-21.7 \%$ & $\pm 4.4 \%$ & 89 \\
\hline $\mathrm{HC}$ & B100 & HD \& LD Dyno & $-13.4 \%$ & $\pm 9.2 \%$ & 122 \\
\hline $\mathrm{NO}_{\mathrm{x}}$ & B20 & HD \& LD Dyno & $+4.7 \%$ & $\pm 1.6 \%$ & 227 \\
\hline $\mathrm{NO}_{\mathrm{x}}$ & B100 & HD \& LD Dyno & $+7.5 \%$ & $\pm 2.4 \%$ & 143 \\
\hline $\mathrm{CO}$ & B20 & $\begin{array}{l}\text { HD, LD Dyno \& } \\
\text { HD On-road }\end{array}$ & $-5.4 \%$ & $\pm 2.9 \%$ & 286 \\
\hline PM & B20 & $\begin{array}{c}\text { HD Dyno \& HD } \\
\text { On-road }\end{array}$ & $-14.5 \%$ & $\pm 13.9 \%$ & 137 \\
\hline PM & B20 & LD Dyno & $-5.8 \%$ & $\pm 4.9 \%$ & 109 \\
\hline $\begin{array}{c}\text { Fuel } \\
\text { Economy }\end{array}$ & B20 & HD \& LD Dyno & $-1.8 \%$ & $\pm 1.1 \%$ & 94 \\
\hline
\end{tabular}

\section{References}

The literature that was reviewed in this analysis included 19 published studies using dynamometers for HD vehicles, 14 studies using on-road data for HD vehicles, and 47 studies using dynamometers for LD vehicles. Due to space limitations these references are not included in the reference list, but are available upon request.

[1] R. L. McCormick, The impact of biodiesel on pollutant emissions and public health, Inhalation Toxicology 19, 2007, pp. 1033 - 1039.

[2] M. Lapuerta, O. Armas, J. Rodriguez-Fernandez, Effects of biodiesel fuels on diesel engine emissions, Progress in Energy and Combustion Science 34, 2008, pp. 198- 224.

[3] J. Yanowitz, R. L. McCormick, Effect of biodiesel blends on North American heavy-duty diesel engine emissions, European Journal of Lipid Science and Technology 111, 2009, pp. 763-772.

[4] S. K. Hoekman, A. Gertler, A. Broch, C. Robbins, Investigation of biodistillates as potential blendstocks for transportation fuels, Coordinating Research Council, CRC Project No. AVFL-17, 2009. 